\title{
Choosing Excellence
}

\author{
Douglas Doucette
}

Excellence is never an accident. It is always the result of high intention, sincere effort, and intelligent execution; it represents the wise choice of many alternatives — choice, not chance, determines your destiny. -Aristotle

$\mathrm{H}$ ow do we know when we have done a good job? An excellent job? For such assessments, we often rely on our leaders, those managers and clinicians in our organization who set and help us reach the necessarily high expectations of our profession through training, development, and inspiration. The profession of pharmacy has high standards, which guide us in our responsibility to care for the sickest of the sick in our communities, clinics, and hospitals. The Canadian Society of Hospital Pharmacists (CSHP) continues to provide leadership and guidance to its members in reaching those high standards for excellence in practice, as shown by several recent publications and programs.

In 2011, in cooperation with CSHP, a group of Canadian hospital pharmacists formed the Canadian cpKPI Collaborative to develop a core set of clinical pharmacy key performance indicators (cpKPIs) based on evidence of high-quality care in the context of clinical pharmacy services provided to inpatients (see Ann Pharmacother. 2015;49[6]:656-69 or the "Quick Reference Guide” available at https://www.cshp.ca/clinical-pharmacy-keyperformance-indicators). Collecting cpKPI data in hospital settings is expected to improve quality of care, advance practice toward desired evidence-informed patient outcomes, and elevate professional accountability and transparency. The Canadian cpKPI Collaborative is working to implement these cpKPIs, which will allow hospital pharmacists to focus their efforts on patient care activities that influence important outcomes, such as mortality and hospital readmissions.

In 2016, CSHP developed a set of position statements for patient-focused pharmacy practice. These position statements on pharmacy practice in hospitals and other collaborative healthcare settings (available at https://www.cshp.ca/position-statements) describe a "desired and achievable level of performance that is applicable to the practice of pharmacy in a healthcare organization, regardless of geographical location, experience, or area of practice." The document reflects on patients' experiences, focusing on their values, beliefs, and desires, while attempting to engage them in managing their health needs. The patient-centred position statements are presented in 3 sections: practice model for patientcentred care, partners, and stewardship. These statements provide guidance for pharmacy practitioners and leaders as they strive toward practice excellence for hospitals and other collab-

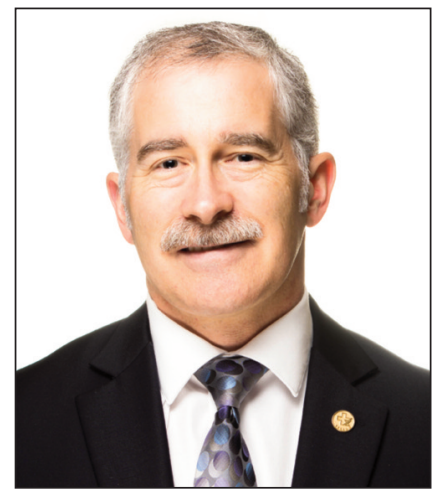
orative healthcare settings.

The Excellence in Hospital Pharmacy program (https:// www.cshp.ca/excellence) was launched at the 2016 Professional Practice Conference as the successor to the highly successful CSHP 2015 initiative. Excellence, a multiyear program aligned with the latest CSHP Strategic Plan, is intended to assist members in focusing their efforts toward "fostering excellence and innovation in patient care." The program has 3 priority themes: Patient Engagement/Patient Centredness; Best Practice, Including Patient Safety; and Effective Communication and Collaborative Practice. The program has 6 objectives, a comprehensive work plan, performance measures, and targets to measure success. Expect to hear much more about this program from its national steering committee, which comprises representatives from all CSHP branches, a pharmacy technician, a pharmacy student, and a patient experience advisor.

Hospital pharmacy has earned a high level of trust from patients and healthcare providers as a result of excellence in the care and services we deliver in our teams and institutions. As pharmacists, we need not be perfect, but we owe it to our patients to strive for excellence.

Douglas Doucette, BSC(Pharm), PharmD, FCSHP, became President Elect and External Liaison for the Canadian Society of Hospital Pharmacists at the Board meeting following his election during the Annual General Meeting in September 2017. 